\title{
Topological and histological description of preoptic area and hypothalamus in cardinal tetra Paracheirodon axelrodi (Characiformes: Characidae)
}

\author{
Laura Rincón ${ }^{1}$, Martha J. Obando ${ }^{2}$, Mario O. Tovar ${ }^{2}$, Matías Pandolfi ${ }^{1}$ and \\ Hernan Hurtado ${ }^{2}$
}

Topological and histological descriptions of the preoptic area and hypothalamus of the cardinal tetra Paracheirodon axelrodi were performed. Standard histological paraffin sections were used and stained with Nissl technique, and plastic sections for high-resolution optic microscopy (HROM). The preoptic area showed some differences related to the location of the magnocellular preoptic nucleus (PM) and the size of the neurons in this region, as they were the biggest in all the preoptic area. Additionally, within the preoptic area, the different structures that comprise the organum vasculosum of the lamina terminalis (OVLT) were identified and characterized. The hypothalamus could be subdivided in three regions - the ventral, the dorsal and the caudal hypothalamic regions - neuron morphology, size and staining pattern were similar in all of them.

Keywords: Brain, High resolution optic microscopy (HROM), Organum vasculosum of the lamina terminalis (OVLT).

Se realizó la descripción topológica e histológica del área preóptica e hipotálamo en el Neón cardenal Paracheirodon axelrodi. Se usaron cortes obtenidos con tecnicas histológicas estándar, coloreados con técnica de Nissl y secciones en resina con microscopía óptica de alta resolución (MOAR). El área preóptica muestra algunas diferencias relacionadas con la localización del núcleo preóptico magnocelular (PM) y el tamaño de algunas neuronas en esta región, puesto que estas eran las más grandes de toda el área preoptica. Adicionalmente, dentro del área preóptica, fue posible identificar y caracterizar las diferentes estructuras que componen el órgano vasculoso de la lámina media (OVLM). El hipotálamo puede sudividirse en tres zonas: la zona hipotalámica ventral, la zona hipotalámica dorsal y la zona hipotalámica caudal. La morfología de las neuronas de los núcleos que comprenden las diferentes zonas del hipotálamo tiene tamaño, forma y coloración similar.

Palabras Clave: Cerebro, Microscopía óptica de alta resolucion (MOAR), Órgano vasculoso de la lámina terminal (OVLT).

\section{Introduction}

The teleost central nervous system (CNS) plays an important role in the regulation of reproduction. First, it integrates environmental signals received through the sensorial system and internal signals regulated by the hypophysiotropic system. Second, it transmits the integrated signals to endocrine effectors through hypophysal modulation that results in the onset of reproduction-specific behaviours and gonadal maturation (Butler, Hodos, 2005; Cerdá-Reverter, Canosa, 2009).

Pioneer studies revealed similarities between the hypothalamus-hypophysis system of fish and other vertebrates, and its link with the CNS and endocrine system to regulate several vital processes (Kapoor, Khanna, 2004; Pogoda, Hammerschmidt, 2007). However, studies in teleost fish have shown that the regulation of hypophysiary activity is not restricted to the hypothalamus, as it was once believed, but it extends to other brain areas such as the ventral telencephalon and the preoptic area (Kah et al., 1993; Trudeau et al., 1997). The two main areas in the anterior-ventral brain containing neuronal somas whose axons reach the neurohypophysis in teleost fishes are the preoptic area and the hypothalamus (Palay, 1945).

The preoptic area includes different nuclei that are functionally related to the ventricular and tuberal regions of the hypothalamus forming a functional and structural unit (Meek, Nieuwenhuys, 1998). In fish, the hypothalamus is

\footnotetext{
${ }^{1}$ Laboratorio de Neuroendocrinología y Comportamiento, DBBE, FCEN, UBA e IBBEA, CONICET-UBA, Ciudad Universitaria, Intendente Güirlades 2160, C1428EHA. Ciudad Autónoma de Buenos Aires, Argentina. (LR) laura.rinconc27@gmail.com (corresponding author), (MP) pandolfi@bg.fcen.uba.ar

${ }^{2}$ Grupo de Ictiología, Laboratorio de Embriología, Programa de Biología Aplicada, Facultad de Ciencias Básicas y Aplicadas, Universidad Militar Nueva Granada. Campus Rio Grande. Kilómetro 2 Vía Cajicá, Colombia. (MJO) martha.obando@unimilitar.edu.co, (MOT) bioswal@gmail.com, (HH) hernan.hurtado@unimilitar.edu.co
} 
the biggest part of the diencephalon, located in the ventral brain surface, ventral to the third ventricle. It is connected to the hypophysis through the infundibulum, which contains neuroendocrine fibers, which proceed from preoptic and hypothalamic nuclei (Wullimann et al., 1996; Cerdá-Reverter, Canosa, 2009). For this reason, these two areas preoptic area and hypothalamus are treated as a single complex by endocrinologists when discussing hypophysiotropic control in fish. Secretory neurons of the preoptic area extend their fibers directly to the posterior hypophysis or neurohypophysis (Norris, 2007; Cerdá-Reverter, Canosa, 2009).

The cardinal tetra, Paracheirodon axelrodi (Schlutz, 1956), is a characiform fish of the most exported ornamental species in Colombia, Brazil and Venezuela (BlancoCastañeda, 2002; Ruiz et al., 2007; Mancera-Rodríguez, Álvarez-León, 2008; COPESCAL, 2009; CCI, 2010). Therefore, several studies have focused on understanding its basic biology, as an imperative step to find sustainable exploitation strategies (Burton et al., 1998; Walker, 2004; Anjos, Anjos, 2006; Oliveira et al., 2008; Tovar et al., 2009; Brito, Bazzoli, 2009; Gómez-Ramírez et al., 2011; ObandoBulla et al., 2013). In spite of these efforts, very little is known about the neuroendocrinology of reproduction in cardinal tetra, particularly regarding the neuroanatomical organization of the preoptic-hypothalamus-hypophysis complex. Thus, the aim is to describe topologically and histologically the preoptic and hypothalamic areas of $P$. axelrodi.

\section{Materials and Methods}

All procedures described in the following sections take into account the current regulations and protocols for ethic handling and animal care in research (AVMA, 2001; CCAC, 2003). Twelve adult animals were used for the analysis, mean standard length $\left(L_{\mathrm{S}}\right) \pm$ S.D. $=2.33 \pm 0.30 \mathrm{~cm}$, mean total length $\left(L_{\mathrm{T}}\right) \pm$ S.D. $=2.81 \pm 0.39 \mathrm{~cm}$, mean weight \pm S.D. $=0.26 \pm 0.12 \mathrm{~g})$. All animals were anesthetized with $(0.1 \mathrm{~g} / \mathrm{L})$ benzocaine and sacrificed by medullar cervical sectioning (Scherck, Moyle, 1990). Whole brain was carefully dissected and processed as follows.

Sample processing. Eight samples were processed for standard paraffin sectioning and Nissl staining (Gridley, 1960). Four samples were processed for high-resolution optic microscopy (HROM) (Caldas et al., 1993; Castañeda et al., 2013). For Nissl staining, samples were fixed using $4 \%$ formaldehyde, dehydrated and embedded in paraffin (Merck millipore $\mathbb{C}$, Alemania). Serial $6 \mu \mathrm{m}$ cross sections were obtained and stained with the Cresyl violet acetate dye (Sigma, USA). For HROM, samples were fixed with a mixture of formaldehyde and glutaraldehyde, post fixed with Osmium tetroxide (Polysciences Inc, USA) and embedded in Poli/Bed 812® (Polysciences Inc, USA) plastic resin. One micrometer cross sections were obtained and stained with toluidine blue dye (Sigma, USA) (Gridley, 1960; Caldas et al., 1993).
The topology of the main preoptic and hypothalamic nuclei was established based on previously published fish brain atlases from: zebrafish, Danio rerio (Hamilton, 1822) (Wullimann et al., 1996); medaka, Oryzias latipes (Temminck \& Schlegel, 1846) (Anken, Bourrat, 1998; Ishikawa et al., 1999) and lubina, Dicentrarchus labrax (Linnaeus, 1758) (Cerdá-Reverter, Canosa, 2009). Additionally, use quantitative and qualitative criteria such as neuron size, neuron shape, staining intensity, cytoplasm distribution pattern, nucleus location, spatial distribution and degree of neuronal grouping per nucleus in the different nuclei identified. In order to show the location of the different nuclei, schematics diagrams were performed indicating the level at which cross sections were obtained, labelled from A to L (Fig. 1). The zero level corresponds to the start of the postoptic commissure (Cpop) and was labelled as E. Each cross section was diagrammed using the "Image J" software (Rasband, 2012) and indicates the distance to the zero level in micrometres $(\mu \mathrm{m})$.

Morphometrics and statistical analysis. Four nonconsecutive cross section images from the different levels identified were used for the morphometric analysis. Using the "Image J" software (Rasband, 2012), neuronal body area and perimeter were measured and recorded. All data were tested for normality and homoscedasticity with the KolmogorovSmirnov test and Levene's test, repectively, for single samples using the SPSS software (SPSS Inc, 2009). Once statistical assumptions were confirmed, one way analysis of variance (ANOVA) was performed followed by a Bonferroni multiple comparisons test (the level of significance was $P<0.05$ ) using the GraphPadPrism, Inc $\mathbb{C} 2007$ software in order to determine significant differences between neuron perimeter and area in the different nuclei identified.

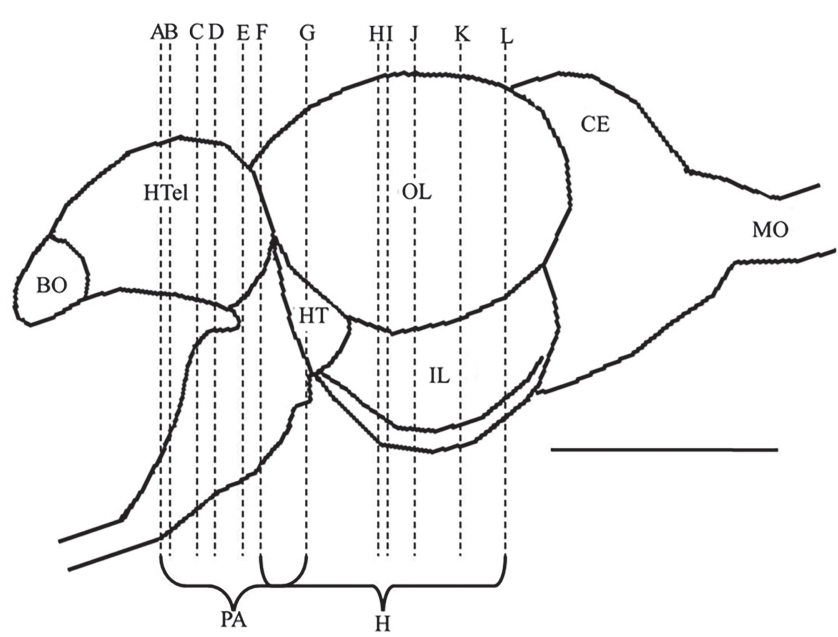

Fig. 1. Schematic side view of Paracheirodon axelrodi brain indicating section levels (letters A to L) comprising the preoptic area (AP) and hypothalamus (H). The zero level is indicated by the letter E. Olfactory bulbs (OB), cerebellum (CE), tuberal hypothalamus (TH), telencephalic hemispheres $(\mathrm{TelH})$, inferior lobes (IL), optic lobes (OL), medulla oblongata (MO) and optic nerve (NII). Bar $=1000 \mu \mathrm{m}$. 
Abbreviations. Ansulate commissure (Cans); anterior mesenchepalic cerebellar tract (TMCa); anterior part of the parvocellular preoptic nucleus $(\mathrm{PPa})$; anterior preglomerular nucleus (PGa); anterior tuberal nucleus (ATN); caudal zone of the periventricular hypothalamus (Hc); central nucleus of the interior lobe (CIL); central nucleus of the semicircular torus (TSc); central posterior thalamic nucleus $(\mathrm{CP})$; central pretectal nucleus (CPN); central zone of D (Dc); cerebellum (CE); diencephalic ventricle (DiV); diffuse nucleus of the interior lobe (DIL); dorsal accessory optic nucleus (DAO); dorsal nucleus of the $\mathrm{V}(\mathrm{Vd})$; dorsal part of the entopeduncular nucleus (ENd); dorsal posterior thalamic nucleus (DP); dorsal tegmental nucleus (DTN); dorsal telencephalic area (D); dorsal zone of the D (Dd); dorsal zone of the periventricular hypothalamus (Hd); dorsomedial optic tract (DOT); epiphysis (EP); glial cells (Gl); hypophysis $(\mathrm{H})$; inferior lobes (IL); intermediate thalamic nucleus (I); interpeduncular nucleus (Nln); lateral division of the cerebellar valvula (Val); lateral forebrain bundle (LFB); hypothalamic lateral nucleus $(\mathrm{Hl})$; lateral longitudinal fascicle (LLF); lateral preglomerular nucleus (PGl); lateral recess of the diencephalic ventricle (LR); lateral torus (TLa); lateral valvular nucleus (NLV); lateral zone of the D (Dl); longitudinal torus (TL); magnocellular preoptic nucleus (PM); magnocellular superficial pretectal nucleus (PSm); mammillary body (CM); medial division of the cerebellar valvula (Vam); medial longitudinal fascicle (MLF); medial preglomerular nucleus (PGm); medial zone of the $\mathrm{D}(\mathrm{Dm})$; medulla oblongata $(\mathrm{MO})$; nucleus of the MLF (NMLF); nucleus taeniae (NT); oculomotor nerve (III); oculomotor nucleus (NIII); olfactory bulbs (OB); optic chiasm (CO); optic lobes $(\mathrm{OL})$; optic nerve (NII); optic tectum $(\mathrm{TeO})$; optic tract (OT); paraventricular organ (PVO); pars dorsalis of the anterior commissure (Cantd); pars ventralis of the anterior commissure (Cantv); parvocellular preoptic nucleus (PP); parvocellular superficial pretectal nucleus (PSp); perilemniscal nucleus (PL); peri-ventricular grey zone of the optic tectum (PGZ); peri-ventricular nucleus of the posterior tuberculum (TPp); post commissural nucleus of the $\mathrm{V}(\mathrm{Vp})$; posterior commissure (Cpost); posterior part of the parvocellular preoptic nucleus (PPp); posterior recess of the diencephalic ventricle (PR); posterior tuberal nucleus (PTN); posterior zone of the D (Dp); postoptic commissure (Cpop); preoptic area (AP); pretecto mammillary tract (TPM); retroflex fasciculus (FR); semicircular torus (TS); subglomerular nucleus (SG); supra commissural nucleus of the V (Vs); suprachiasmatic nucleus (SC); tanycytes (T); tectal ventricle (TeV); tectobulbar tract (TTB); telencephalic hemispheres $(\mathrm{TelH})$; tertiary gustatory nucleus (TGN); tuberal hypothalamus (TH); vascular lacuna of the area postrema (Vas); organum vasculosum of the lamina terminalis (OVLT); ventral habenular nucleus (Hav); ventral nucleus of the $\mathrm{V}(\mathrm{Vv})$; ventral part of the entopeduncular nucleus
(ENv); ventral part of the periventricular pretectal nucleus $(\mathrm{PPv})$; ventral telencephalic area $(\mathrm{V})$; ventral zone of the periventricular hypothalamus (Hv); ventro-lateral nucleus of the semicircular torus (TSvl); ventro-lateral optic tract (VOT); ventro-lateral thalamic nucleus (VL); ventromedial thalamic nucleus (VM).

\section{Results}

Preoptic area. The preoptic area in $P$. axelrodi extends from the medial region of the ventral telencephalon to the beginning of the diencephalon (Fig. 1). It surrounds the anterior diencephalic ventricle (DiV), also known as the third ventricle. Anteriorly, it is limited by the pars dorsalis (Cantd) and pars ventralis (Cantv) of the anterior commissure (Figs. 2a-b). Dorsally, it is limited by the dorsal telencephalic area (D), the post commissural nucleus of the ventral telencephalon $(\mathrm{Vp})$, the supra commissural nucleus of the ventral telencephalon (Vs), the ventro-lateral thalamic nucleus (VL) and the ventromedial thalamic nucleus (VM) (Figs. 2a-e). Ventrally, it is adjacent to the optic chiasm (CO) and the postoptic commissure (Cpop) (Figs. 2c-f, 3g). Posteriorly, it borders the ventral zone of the periventricular hypothalamus (Hv) (Fig. 3g).

The magnocellular preoptic nucleus (PM) (Figs. 2a-c) is located in the telencephalon, dorsal to the parvocellular preoptic nucleus (PP). It adopts a more diffused disposition towards the caudal region. The parvocellular nucleus is divided in two regions, the anterior part (PPa), located ventrally in the medial telencephalon (Figs. 2a-c), and the posterior part (PPp), located ventrally between the caudal telencephalon and the anterior diencephalon (Figs. 2d-f, $3 \mathrm{~g})$. The most ventral margin of the $\mathrm{DiV}$ is surrounded by the suprachiasmatic nucleus (SC), situated dorsal to the $\mathrm{CO}$ and ventral to the PPp (Figs. 2d-f, 3g).

Neurons of the PM are spherical and stain moderately with Cresyl Violet acetate and toluidine blue. They are characterized by being dispersed toward the PP dorsolateral region. They have little visible cytoplasm and a spherical central nucleus with one or more nucleoli (Figs. 4a-b). Neurons in the PPa and PPp are spherical and stain strongly with Cresyl Violet acetate and toluidine blue. They form compact groups near the ventral PM region. Visible cytoplasm is scarce and the nucleus occupies the center of the cell (Figs. 4a-b). In the SC, spherical neurons stain strongly with Cresyl Violet acetate and toluidine blue. They possess little visible cytoplasm and a central nucleus (Fig. 4c).

Regarding neuron size (Fig. 6a), PM neurons $(\mathrm{n}=318)$ are significantly larger in terms of area (mean \pm S.D. 27.72 $\left.\pm 4.73 \mu \mathrm{m}^{2}\right)$ and perimeter (mean \pm S.D. $19.66 \pm 1.86 \mu \mathrm{m}$ ) than those in the $\mathrm{PPa}\left(12.03 \pm 0.97 \mu \mathrm{m}^{2} ; 12.89 \pm 0.51 \mu \mathrm{m}\right.$; $\mathrm{n}=452), \operatorname{PPp}\left(12.78 \pm 0.68 \mu \mathrm{m}^{2} ; 13.23 \pm 0.35 \mu \mathrm{m} ; \mathrm{n}=\right.$ $326)$ and $\mathrm{SC}\left(12.41 \pm 0.43 \mu \mathrm{m}^{2} ; 13.09 \pm 0.25 \mu \mathrm{m} ; \mathrm{n}=336\right)$ $(P<0.0001)$. 
a

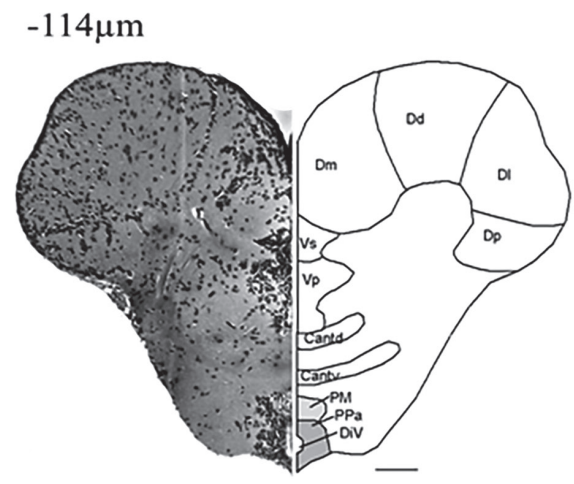

C

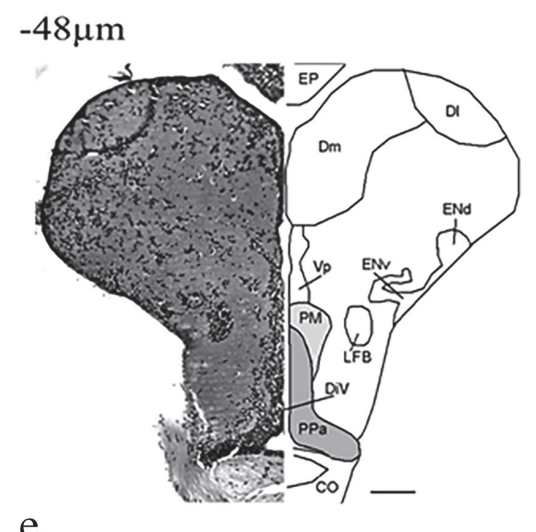

e

$0 \mu \mathrm{m}$

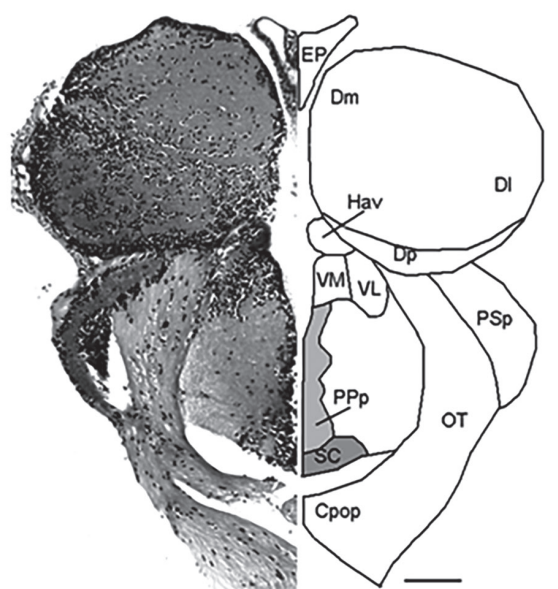

b

$-84 \mu \mathrm{m}$

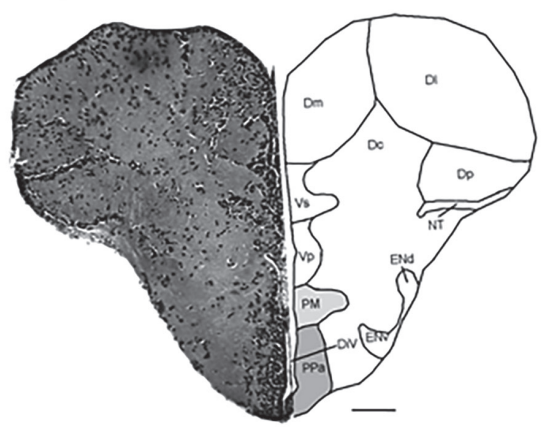

d

$-30 \mu \mathrm{m}$

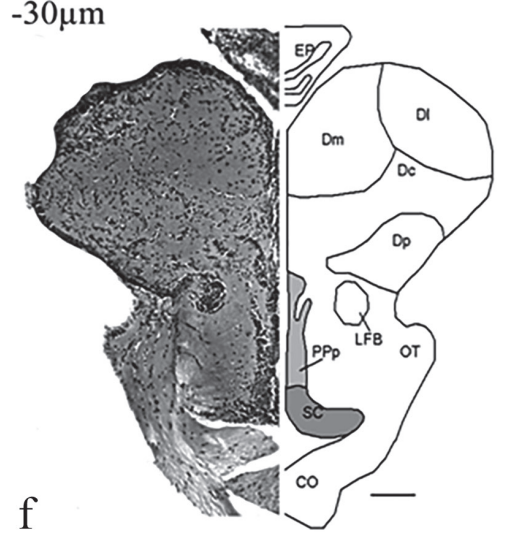

$54 \mu \mathrm{m}$

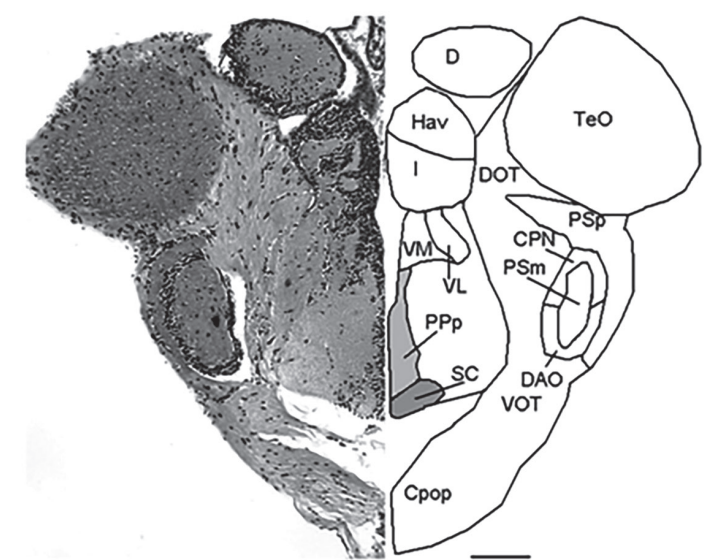

Fig. 2. Cross section diagrams showing levels a to f from Fig. 1. The numbers indicate the distance in $\mu \mathrm{m}$ from level zero (E). Pars dorsalis of the anterior commissure (Cantd), pars ventralis of the anterior commissure (Cantv), optic chiasm (CO), postoptic commissure (Cpop), dorsal telencephalic area (D), dorsal accessory optic nucleus (DAO), central zone of the $\mathrm{D}(\mathrm{Dc})$, dorsal zone of the $\mathrm{D}(\mathrm{Dd})$, lateral zone of the $\mathrm{D}(\mathrm{Dl})$, diencephalic ventricle $(\mathrm{DiV})$, medial zone of the $\mathrm{D}$ $(\mathrm{Dm})$, dorsomedial optic tract (DOT), posterior zone of the $\mathrm{D}(\mathrm{Dp})$, dorsal part of the entopeduncular nucleus (ENd), ventral part of the entopeduncular nucleus (ENv), epiphysis (EP), ventral habenular nucleus (Hav), intermediate thalamic nucleus (I), lateral forebrain bundle (LFB), nucleus taeniae (NT), optic tract (OT), lateral preglomerular nucleus (PGl), magnocellular preoptic nucleus (PM), anterior part of the parvocellular preoptic nucleus (PPa), posterior part of the parvocellular preoptic nucleus (PPp), magnocellular superficial pretectal nucleus (PSm), parvocellular superficial pretectal nucleus (PSp), suprachiasmatic nucleus (SC), optic tectum (TeO), ventral telencephalic area (V), dorsal nucleus of the $\mathrm{V}(\mathrm{Vd})$, ventro-lateral thalamic nucleus (VL), ventro-medial thalamic nucleus (VM), ventro-lateral optic tract (VOT), post commissural nucleus of the $\mathrm{V}(\mathrm{Vp})$, supra commissural nucleus of the $\mathrm{V}(\mathrm{Vs})$, ventral nucleus of the $\mathrm{V}(\mathrm{Vv})$. Nissl staining. Bar $=100 \mu \mathrm{m}$. 
g

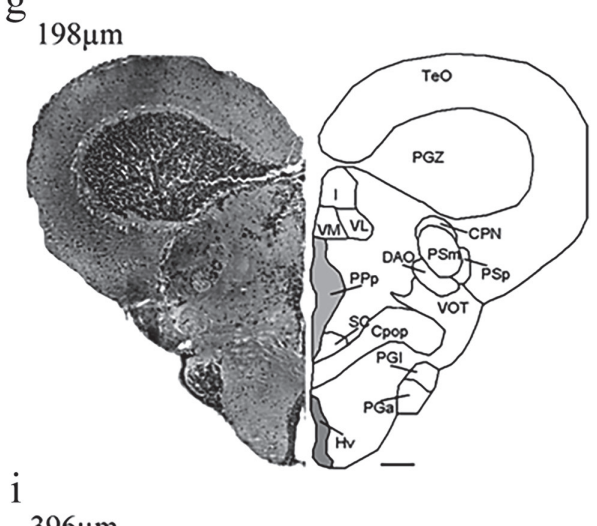

$396 \mu \mathrm{m}$

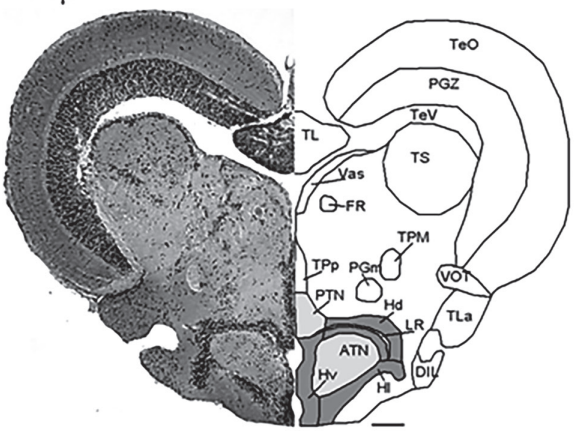

$\mathrm{k}$

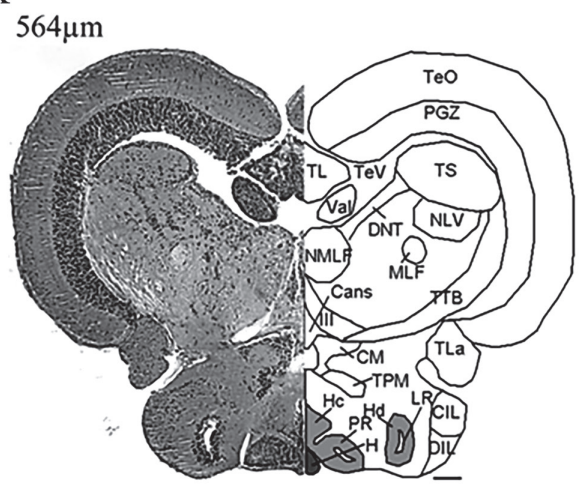

$\mathrm{h}$
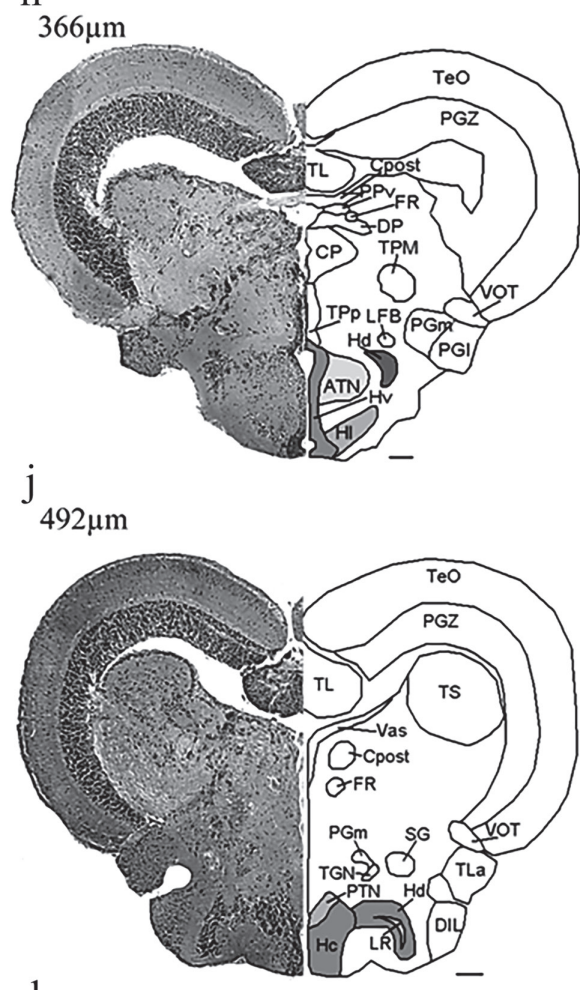

1

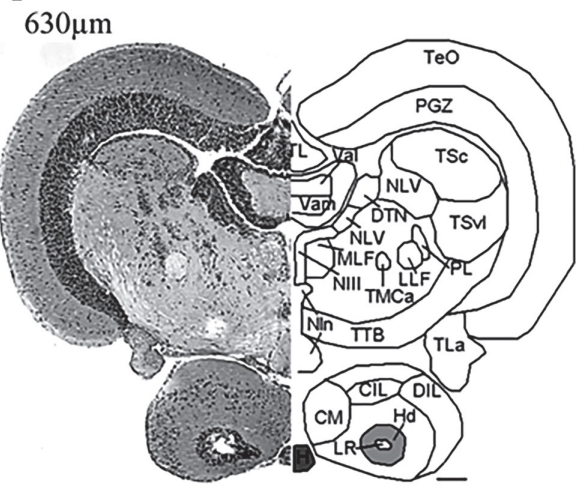

Fig. 3. Cross section diagrams showing levels $g$ to 1 from Fig. 1. The numbers indicate the distance in $\mu \mathrm{m}$ from the zero level (E). Anterior tuberal nucleus (ATN), ansulate commissure (Cans), central nucleus of the interior lobe (CIL), mammillary body $(\mathrm{CM})$, central posterior thalamic nucleus $(\mathrm{CP})$, central pretectal nucleus $(\mathrm{CPN})$, postoptic commissure (Cpop), posterior commissure (Cpost), dorsal accessory optic nucleus (DAO), diffuse nucleus of the interior lobe (DIL), dorsomedial optic tract (DOT), dorsal posterior thalamic nucleus (DP), dorsal tegmental nucleus (DTN), retroflex fasciculus (FR), hypophysis (H), caudal zone of the periventricular hypothalamus ( $\mathrm{Hc})$, dorsal zone of the periventricular hypothalamus (Hd), hypothalamic lateral nucleus $(\mathrm{Hl})$, ventral zone of the periventricular hypothalamus $(\mathrm{Hv})$, intermediate thalamic nucleus (I), oculomotor nerve (III), lateral longitudinal fascicle (LLF), lateral recess of the diencephalic ventricle (LR), medial longitudinal fascicle (MLF), oculomotor nucleus (NIII), interpeduncular nucleus (Nln), lateral valvular nucleus (NLV), nucleus of the MLF (NMLF), anterior preglomerular nucleus (PGa), lateral preglomerular nucleus (PGl), medial preglomerular nucleus (PGm), periventricular grey zone of the optic tectum (PGZ), perilemniscal nucleus (PL), parvocellular preoptic nucleus (PP), ventral part of the periventricular pretectal nucleus ( $\mathrm{PPv})$, posterior recess of the diencephalic ventricle (PR), magnocellular superficial pretectal nucleus (PSm), parvocellular superficial pretectal nucleus (PSp), posterior tuberal nucleus (PTN), suprachiasmatic nucleus (SC), subglomerular nucleus (SG), optic tectum $(\mathrm{TeO})$, tectal ventricle $(\mathrm{TeV})$, tertiary gustatory nucleus (TGN), longitudinal torus (TL), lateral torus (TLa), anterior mesenchepalic cerebellar tract (TMCa), pretecto mammillary tract (TPM), periventricular nucleus of the posterior tuberculum (TPp), semicircular torus (TS), central nucleus of the semicircular torus (TSc), ventrolateral nucleus of the semicircular torus (TSvl), tectobulbar tract (TTB), lateral division of the cerebellar valvula (Val), medial division of the cerebellar valvula (Vam), vascular lacuna of the area postrema (Vas), ventrolateral thalamic nucleus $(\mathrm{VL})$, ventro-medial thalamic nucleus $(\mathrm{VM})$, ventrolateral optic tract $(\mathrm{VOT})$. Nissl staining. Bar $=100 \mu \mathrm{m}$. 

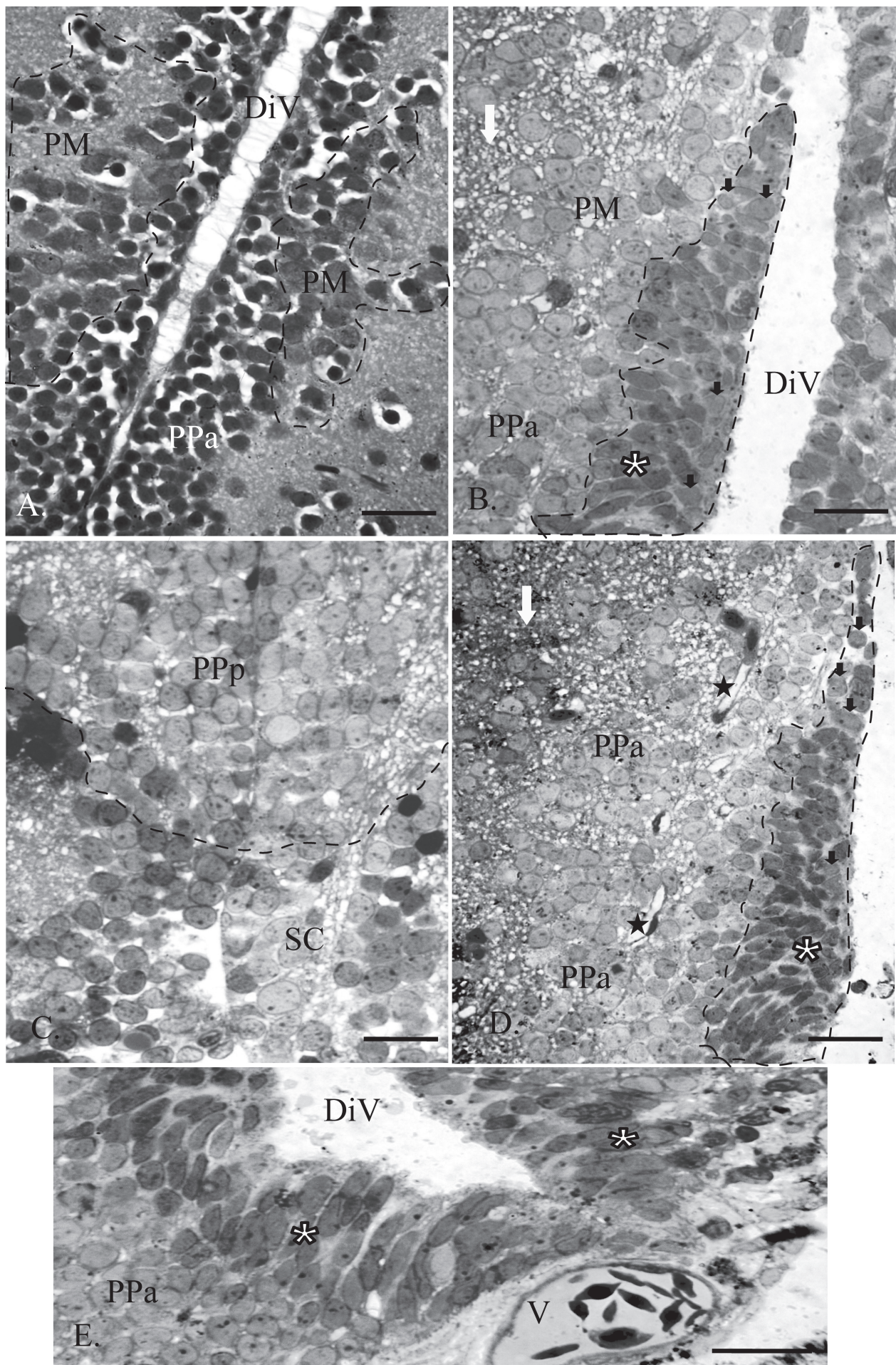

Fig. 4. Cross section photomicrographs of the telencephalon of Paracheirodon axelrodi; a. Delineated area shows neurons of the magnocellular preoptic nucleus (PM). Anterior part of the parvocellular preoptic nucleus (PPa) and diencephalic ventricle (DiV); b. Delineated area shows the anterior part of the organum vasculosum of the lamina terminalis (OVLT). Glial cells (black arrowhead), nerve fibers detail (white arrow), tanycytes (asterisk) and neurons that correspond to magnocellular preoptic nucleus (PM), anterior part of the parvocellular preoptic nucleus (PPa) and diencephalic ventricle (DiV); c. Delineated area shows the posterior part of the parvocellular preoptic nucleus (PPp) and the suprachiasmatic nucleus (SC); d. Delineated area shows posterior part of OVLT. Glial cells (black arrowhead), nerve fibers detail (white arrow), internal capillaries (stars), tanycytes (asterisk) and neurons that correspond to the anterior part of the parvocellular preoptic nucleus (PPa); e. Detail of the most ventral part of the OVLT shows: venule (V), tanycytes (asterisk) and neurons of the anterior part of the parvocellular preoptic nucleus (PPa). Nissl staining (a). Toluidine blue staining (b-e). Bar $=10 \mu \mathrm{m}$. 
Additionally, a cellular layer commonly known as the organum vasculosum of the lamina terminalis (OVLT) was identified in the preoptic area surrounding the DiV. The OVLT is a circumventricular organ made up of a layer of ependymal cells, which contains tanycytes, and another more diversified layer of subependymal cells, that contains glial cells, nervous fibers and small capillaries, as well as the PPa neurons (Fig. 4d). Tanycytes (T) in this region are characterized by its spindle cellular shape and central elongated nucleus with one nucleolus (Figs. 4d-e).

Hypothalamus. The hypothalamus, part of the diencephalon, is located ventral to the thalamus and caudal to the optic region (Fig. 1). The anteriormost portion is located caudoventrally to the SC and can be easily recognized due to the highly dense cell groups and its position surrounding the paired latero-caudal ventricular recesses (LR). Anteriorly, it is limited by the postoptic commissure (Cpop) and the PPp (Fig. 3g). Dorsally, it neighbours the limitant zone (LZ), the periventricular nucleus of the posterior tuberculum (TPp) and the paraventricular organ (PVO) (Figs. 3h-i); ventrally it is limited by the hypophysis (Figs. 3k-1).

Several nuclei can be identified in the hypothalamus. They are mostly located towards the ventral diencephalon region along the $\mathrm{DiV}$. Three regions can be clearly distinguishable: the ventral hypothalamic region, the dorsal hypothalamic region and the caudal hypothalamic region. The ventral hypothalamic region corresponds with the ventral zone of the periventricular hypothalamus (Hv), the anterior tuberal nucleus (ATN) and the hypothalamic lateral nucleus (Hl) (Figs. 3g-i). The dorsal hypothalamic region forms the paired latero-caudal ventricular recesses (LR) that are surrounded by a cellular mass known as the dorsal zone of the periventricular hypothalamus (Hd) (Figs. 3h1). The caudal hypothalamic region corresponds with the caudal zone of the periventricular hypothalamus $(\mathrm{Hc})$ and the posterior recess of the diencephalic ventricle (PR). The $\mathrm{Hc}$ is located ventral to the posterior tuberal nucleus (PTN) of the posterior tuberculum (Figs. 3j-k).

The ventral and caudal regions cover most of the tuberal hypothalamus (HT). The dorsal region in turn extends laterally to form the hypothalamic inferior lobes (IL) (Fig. 1). The ILs are separated from the HT by a deep ventral furrow. Within the IL there are two other nuclei, the central nucleus of the interior lobe (CIL) (Figs. 3 k-1) and the diffuse inferior lobe nucleus (DIL) (Figs. 3i-1).

Ventral hypothalamic region. Neurons in the Hv (Fig. 5a) and $\mathrm{Hl}$ (Fig. 5b) are characterized by their spherical shape, little visible cytoplasm, strong Cresyl Violet staining and moderate toluidine blue staining. Cell nuclei are spherical, central, containing a single nucleolus. In the Hv, neurons form a lamina with 7 or more cell layers. Neurons of the Hl form a lamina with 10 or more cell layers in the vicinity of the Hv; whereas in the farthest lateral region this lamina is only 6 to 7 cell layers. Towards the DiV, cylindrically shaped tanycytes $(\mathrm{T})$ can be seen forming a multi-layered structure (Fig. 5a). Neurons in the ATN are spherical, dispersed and strongly stained with Cresyl Violet and toluidine blue. They have little or no visible cytoplasm and are surrounded by amielinic fibers.

Hypothalamic dorsal region. Neurons in the $\mathrm{Hd}$ are spherical, with little cytoplasm, a large nucleus, and stain strongly with Cresyl Violet and weakly with toluidine blue. They can be found forming groups surrounding the LR (Fig. 5c). Towards the medial LR neurons form 5 cell layers increasing to 7 or more cell layers through the lateral LR. In the lateral LR a single layer of spindle shaped tanycytes (T) strongly stained with toluidine blue can also be observed (Fig. 5c).

Caudal hypothalamic region. Neurons in the $\mathrm{Hc}$ are spherical, with scarce cytoplasm, and a large nucleus. They stain strongly with Cresyl Violet and weakly with toluidine blue (Fig. 5d). They cluster in tight groups when surrounding the posterior recess of the diencephalic ventricle (PR), forming more than 6-cell layers. Towards the dorsal nuclei region, these tight groups branch off into several 5-cell layers areas. Some dispersed tanycytes (T) and glial (Gl) cells can also be observed in this region, both cell types strongly stained with toluidine blue. The Hc region is completely surrounded by amielinic fibers, which in some locations are also visible within the nuclei (Fig. 5d). Neurons of the PTN are spherical with scarce cytoplasm, a big central nucleus and one or two nucleoli. They are found dispersed within the nuclei. Some PTN neurons stain weakly while others stain strongly with both Cresyl Violet and toluidine blue. This region also includes some amielinic fibers and glial cells.

Morphometric analysis showed no significant differences for mean area $(P=0.127)$ and perimeter $(P=0.167)$ between neurons of the different hypothalamic regions (Fig. 6b). Mean area \pm S.D.: Hv, $12.01 \pm 2.34 \mu \mathrm{m}^{2}$; Hd, 12.25 $\pm 1.21 \mu \mathrm{m}^{2}$; Hl, $11.59 \pm 0.50 \mu \mathrm{m}^{2}$; Hc, $11.60 \pm 0.70 \mu \mathrm{m}^{2}$; ATN, $13.94 \pm 1.62 \mu \mathrm{m}^{2}$; and PTN, $11.59 \pm 1.17 \mu \mathrm{m}^{2}$. Mean perimeter \pm S.D.: Hv, $12.84 \pm 1.22 \mu \mathrm{m}$; Hd, $12.95 \pm 0.65$ $\mu \mathrm{m} ; \mathrm{Hl}, 12.64 \pm 0.27 \mu \mathrm{m} ; \mathrm{Hc}, 12.63 \pm 0.38 \mu \mathrm{m}$; ATN, 13.82 $\pm 0.78 \mu \mathrm{m}$; and PTN, $12.69 \pm 0.71 \mu \mathrm{m}$. Number of neurons measured (n) for each region was as follows: $\mathrm{Hv}=339, \mathrm{Hd}=$ $399, \mathrm{Hl}=416, \mathrm{Hc}=329, \mathrm{ATN}=270$ and $\mathrm{PTN}=271$.

\section{Discussion}

Preoptic area. Distribution and location of the different preoptic area nuclei in P. axelrodi is similar to those reported for zebrafish, D. rerio (Wullimann et al., 1996), and goldfish, Carassius auratus (Linnaeus, 1758) (Peter, Gill, 1975; Fryer, Maler, 1981). This is probably associated to the fact that all three species are closely related phylogenetically, belonging to the superorder Ostariophysi, being $D$. rerio and $C$. auratus of the Order Cypriniformes and P. axelrodi of the Order Characiformes. 

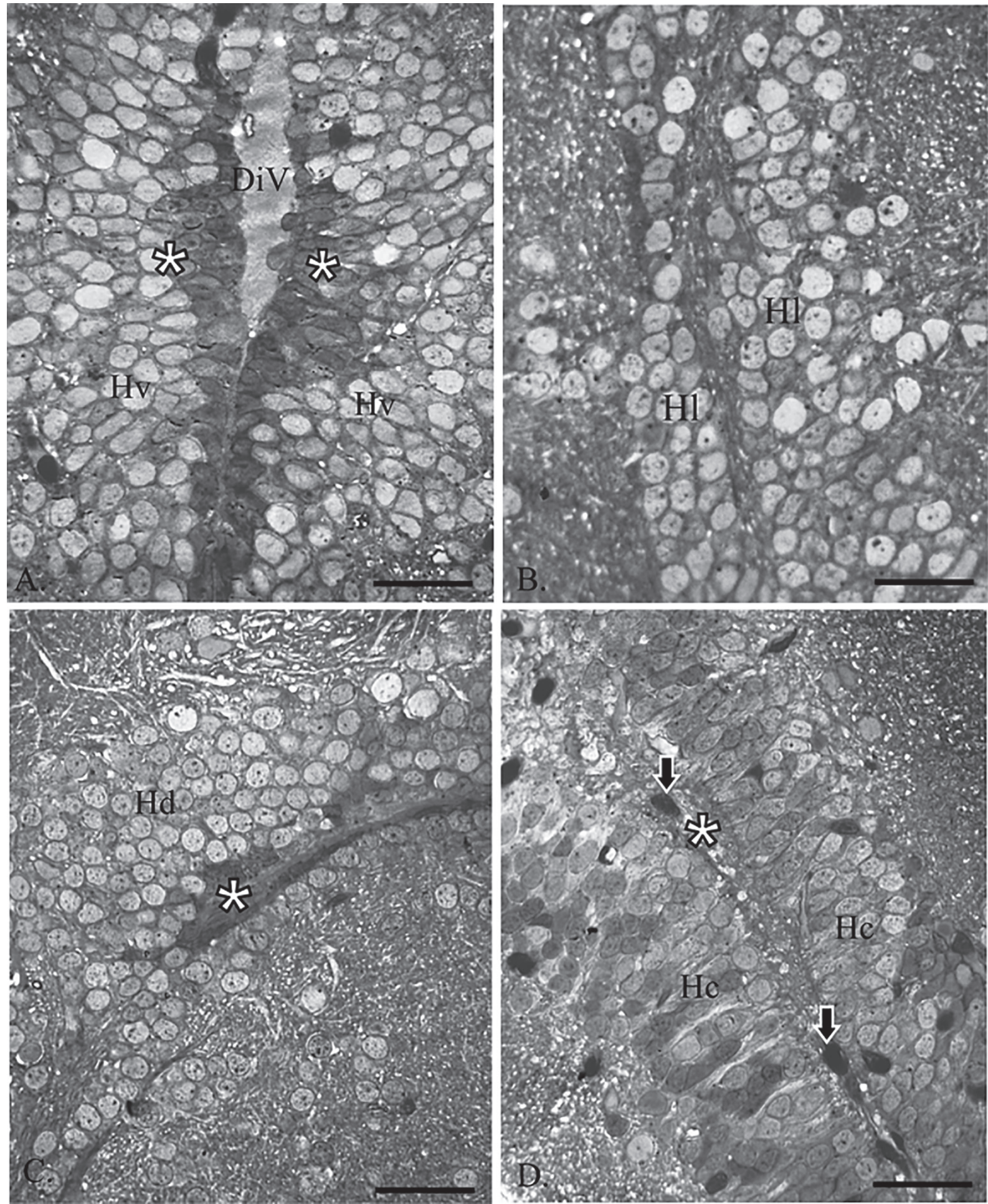

Fig. 5. Cross section photomicrographs of the diencephalon of Paracheirodon axelrodi; a. Photograph showing neurons from the ventral zone of the periventricular hypothalamus (Hv), the diencephalic ventricle (DiV) and tanycytes (asterisk); b. Neurons of the lateral hypothalamic nucleus (Hl); c. Neurons of the dorsal zone of the periventricular hypothalamus (Hd) surrounding the paired latero-caudal ventricular recess (asterisk); d. Neurons of the most ventral part of the caudal zone of the periventricular hypothalamus ( $\mathrm{Hc}$ ) surrounding the posterior recess of the diencephalic ventricle and glial cells (arrows). Toluidine blue staining. Scale bar $=10 \mu \mathrm{m}$. 

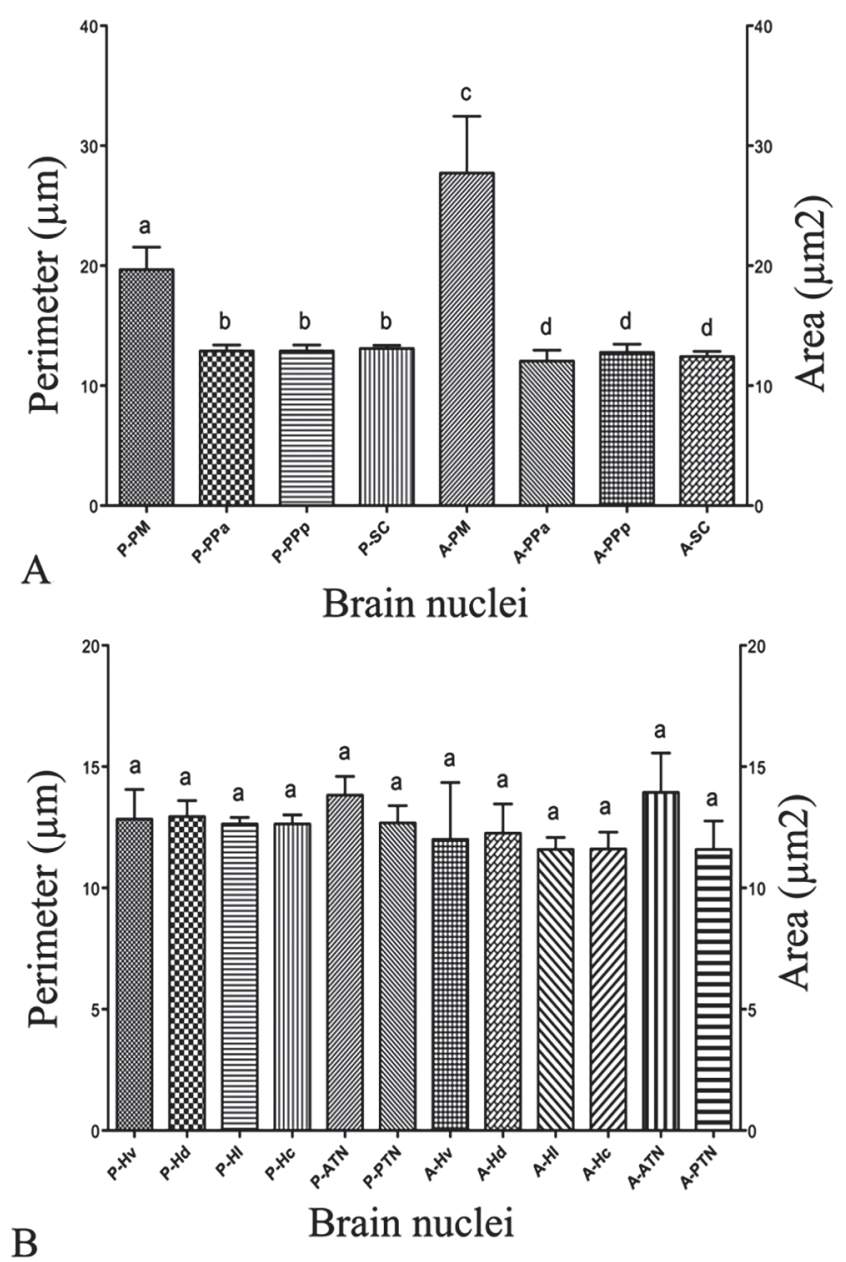

Fig. 6. Morphometry of neurons of preoptic area and hypothalamus. a. Cell soma mean perimeter $(\mathrm{P})(\mu \mathrm{m})$ and area $(\mathrm{A})(\mu \mathrm{m} 2)$ in brain nuclei of the preoptic area of Paracheirodon axelrodi. Each column represents the mean value and standard deviation $(\mathrm{P}<0.0001)$. b. Cell soma mean perimeter $(\mathrm{P})(\mu \mathrm{m})$ and area $(\mathrm{A})(\mu \mathrm{m} 2)$ in brain nuclei of the hypothalamus of Paracheirodon axelrodi. Each column represents the mean value and the standard deviation (Perimeter $\mathrm{P}=0.16$; Area $\mathrm{P}=0.12$ ). Different letters above bars denote significant differences, as assessed by the Bonferroni multiple comparisons test.

Similarities in topological distribution of the nuclei between these related species suggest an evolutionary conservation of structure. However, other related species like lubine, D. labrax (Cerdá-Reverter et al., 2001), and the Atlantic salmon, Salmo salar Linnaeus, 1758 (Peter et al., 1991), show some differences, particularly regarding the distribution of the magnocellular preoptic nuclei (PM), which precludes over generalizing the reported pattern. Detailed studies in other species have to be performed in order to fully characterize this brain region in ostariophysians.

As it has been reported in most true teleost fish, in $P$. axelrodi the preoptic area forms a continuous structure with the hypothalamus. It extends from the medio- posterior telencephalon to the anteriormost diencephalon, disappearing when it reaches the first hypothalamic nuclei (Fryer, Maler, 1981; Nieuwenhuys et al., 1998, CerdáReverter, Canosa, 2009).

In $P$. axelrodi, the location of the preoptic area nuclei (PM and PP) is similar to that reported for D. rerio (Wullimann et al., 1996), the American catfish, Ictalurus punctatus (Rafinesque, 1818) (Striedter, 1990a), O. latipes (Anken, Bourrat, 1998; Ishikawa et al., 1999) and Anguilla japonica Temminck \& Schlegel, 1846 (Mukuda, Ando, 2003). However, when compared with D. labrax, PM distribution is very different. In $P$. axelrodi PM neurons are confined to the most anterior region of the preoptic area, just dorsal to the $\mathrm{PPa}$. Towards the posterior part of the PPa, PM neurons have a disperse distribution, and when PPp neurons become visible, no neurons are seen in the PM. In contrast, PM neurons in D. labrax are located dorsally in the caudal most regions of both the PPa and PPp; No neurons can be observed in the anterior part of the PPa (Cerdá-Reverter et al., 2001). Alternatively, in S. salar and C. auratus, the PM is located ventrally to the PPa and dorsally to the PPp (Peter, Gill, 1975; Fryer, Maler, 1981; Peter et al., 1991).

Additionally, it was not possible to distinguish in $P$. axelrodi the three subdivisions reported by some authors for the PM nuclei - preoptic magnocellular parvocellular nucleus (PMp), magnocellular (PMm) and giganto cellular (PMg) - (Braford, Northcutt, 1983; Butler, Hodos, 2005; Meek, Nieuwenhuys, 1998; Cerdá-Reverter, Canosa, 2009). According to Ekengren (1973), electron microscopy studies have not been able to demonstrate the presence of different cell types in this region (Palay, 1960; Lederis, 1964; Öztan, 1966). Only reports on common eel, Anguilla anguilla (Linnaeus, 1758) (Leatherland, Dodd, 1967), and rutilo, Rutilus rutilus Linnaeus 1758 (Ekengren, 1973), describe two distinct cell types in this brain area, distinguishable by the presence of differently sized secretory granules (Perks, 1969). Based on this evidence, which cellular types comprise the PM is controversial and can vary between species. Variations in the size of PM cells can be due to the amount of their neurosecretory content (Cerdá-Reverter et al., 2001). Similarly, Gómez-Segade et al. (1986) reported that in some species PM cellular neuron size could change seasonally.

Regarding cell size, the PM in P. axelrodi is characterized for having bigger neurons (mean perimeter of $19.66 \pm 1.86$ $\mu \mathrm{m}$ ) than the $\mathrm{PPa}$ (mean perimeter of $12.89 \pm 0.51 \mu \mathrm{m}$ ) and the PPp (mean perimeter of $13.23 \pm 0.35 \mu \mathrm{m}$ ). This is similar to what has been reported for A. japonica, in which PM neurons have a mean perimeter of $20 \mu \mathrm{m}$ while PP neurons have an average perimeter of $5 \mu \mathrm{m}$ (Mukuda, Ando, 2003).

The location of the suprachiasmatic nuclei (SC) in $P$. axelrodi is similar to the one reported for $D$. rerio (Wullimann et al., 1996), O. latipes (Anken, Bourrat, 1998; Ishikawa et al., 1999), A. japonica (Mukuda, Ando, 2003), D. labrax (Cerdá-Reverter et al., 2001) and the Asiatic knife fish, 
Notopterus notopterus (Pallas, 1769) (Baile et al., 2008). In true teleost fish, the $\mathrm{SC}$ receive neuronal projections coming from the retina (Braford, Northcutt, 1983) and seem to project fibers towards the telencephalon and the inferior hypothalamic lobes (Striedter, 1990b; Wullimann, Northcutt, 1988).

Although it is unclear which neuropeptides and neurotransmitters are secreted by neurons of the preoptic area in P. axelrodi, neuropeptides reported to be secreted by PM, PPa, PPp and SC neurons in other teleost fish include Gonadotropin-releasing hormone $(\mathrm{GnRH})$, Thyrothropinereleasing hormone (TRH), Gastrin-releasing peptide (GRP), somatostatin (SST), arginine-vasotocin (AVT), isotocine (IT) and neuropeptide Y (NPY) among others. They have also been reported to secrete neurotransmitters like dopamine (DA), gamma-amino butyric acid (GABA) and serotonin (Fryer, Maler, 1981, Norris, 2007; Greenwood et al., 2008; Cerdá-Reverter, Canosa, 2009; Gomes et al., 2013).

In $P$. axelrodi, the organum vasculosum of the lamina terminalis (OVLT) is located towards the diencephalic ventricular ventral wall, within the preoptic area. The OVLT has been reported in fish (Gómez-Segade et al., 1986; Baile et al., 2008), as well as in other vertebrates (Bosler, 1977; Tsuneki, 1986), and is thought to be comparable to the median eminence of tetrapods. Ultra-structural evidence shows that nervous terminals inside the OVLT contain synaptic vesicles in close contact with fenestrated capillaries, suggesting release of neurohormones directly into the bloodstream. Particularly, terminals containing tyrosine hydroxylase have been observed (Bosler, 1977; Gómez-Segade et al., 1986; Butler, Hodos, 2005). This region also contains high density of GnRH positive fibers in most teleost fish studied thus far (Kah et al., 1993; Gomes et al., 2013).

Tanicytes (T) in the OVLT extend processes towards the ventricle, contacting blood vessels and cerebrospinal fluid. Evidence suggests that $\mathrm{T}$ transport hormones and other molecules from cerebrospinal fluid to hypothalamic nuclei for hypothalamic hormones production and regulation. Therefore, cerebrospinal fluid flow serves as a chemical communication pathway, in conjunction with blood flow, for feedback regulation of hypothalamic hormones (Kah et al., 1993; Butler, Hodos, 2005). Tanycytes are also capable of capturing and transfering substances like thyroxin, peroxidase, GnRH, DA and GABA to other cells (Bosler, 1977). Accordingly, the OVLT might be involved in hormonal feed-back circuits directed toward the central nervous system. However, large molecules might be intracellularly transported through the tanycytes as the fenestrations of endothelial cells might also allow passage of intravascular substances in the opposite direction (Nakai, Naito, 1975).

Hypothalamus. The distribution and location of hypothalamic nuclei in $P$. axelrodi is similar to what has been reported for $D$. rerio (Wullimann et al., 1996), $C$. auratus (Peter, Gill, 1975; Fryer, Maler, 1981), O. latipes
(Anken, Bourrat, 1998; Ishikawa et al., 1999), D. labrax (Cerdá-Reverter et al., 2001) and S. salar (Peter et al., 1991). In general, neuron distribution, size, shape and staining pattern are similar to those previously reported for other related species. Hypothalamic nuclei can be grouped in three regions: the ventral hypothalamic region, the dorsal hypothalamic region and the caudal hypothalamic region, as previously described for $D$. rerio (Wullimann et al., 1996).

The ventral hypothalamic region is known as one of the most important hypophysiotropic brain areas (Fryer, Maler, 1981). In C. auratus, DiI retrograde tracing experiments have detected stained cells in this region after seeding dye crystals into the hypophysis (Anglade et al., 1993). In teleost fish, nuclei of this region ( $\mathrm{Hv}, \mathrm{Hl}$ and $\mathrm{ATN})$ secrete melanin-concentrating hormone (MCH), TRH and GnRH, among other neurohormones. Neurotransmitters and neuromodulators like DA, GABA, NPY and serotonin are also secreted by these nuclei (Butler, Hodos, 2005; Norris, 2007, Cerdá-Reverter, Canosa, 2009, Kawauchi et al., 2009; Gomes et al., 2013).

In teleosts, neurons of the dorsal hypothalamic region secrete neuropeptides such as CCK, GRP, SST and neurotransmitters like serotonin in the Hd nuclei (CerdáReverter, Canosa, 2009). In the caudal hypothalamic region, Hc presents similar neuronal morphological features than Hd. Different reports indicate that neurons in the Hc secrete CCK, CRH, Galanin, NPY, SST, TRH and UI, as well as neurotransmitters like DA, GABA, serotonin and noradrenalin (Norris, 2007; Cerdá-Reverter, Canosa, 2009). Regarding the PTN, it has been reported that neurons in this nuclei secrete TRH (Cerdá-Reverter et al., 2001)

Tanycytes are observed along all three hypothalamic regions described in $P$. axelrodi. They surround the diencephalic ventricle and the posterior (PR) and lateral (LR) recesses. It has been reported that tanycytes in the hypothalamic region have long cytoplasmic processes that converge towards the hypophysis, as it could be observed by retrograde labelling using DiI. Those processes colonize the adenohypophyseal tissue and reach secretory cells. Endocytosis and exocytosis can be observed within the processes, adjacent to secretory cells, indicating that ependymary cells can communicate through the intercellular space with cells in the adenohypophysis (Kah et al., 1993; Butler, Hodos, 2005).

In conclusion, the preoptic area in P. axelrodi shows differences in the distribution of the PM relative to other species. However, the other preoptic nuclei and the hypothalamus are similar in composition to those typically described for other teleost species. Our study of the neuroanatomical organization of the preoptic area and the hypothalamus in $P$. axelrodi provides a useful tool for future morphofunctional studies, such as a detailed inmunohistological characterization in order to identify neurons in these nuclei by their secretion products. Similarly, retrograde and anterograde tracing studies can be useful to determine the origin and destiny of fibers coming into and 
leaving from the preoptic area and hypothalamus in order to truly understand the hypophysiotropic pathway.

\section{Acknowledgments}

This work was supported by Universidad Militar Nueva Granada (grant Vicerrectoría de Investigaciones CIAS 1178) to Hernan Hurtado. This work was carried out in partial fulfilment of the requirements for the BSc degree and was awarded with the maximum recognition to an undergraduate work, Laureate Thesis Award to Laura Rincón.

\section{References}

American Veterinary Medical Association (AVMA). Report of the AVMA panel on euthanasia. J. Am. Vet. Med. Assoc. 2001; 218(5):669-96.

Anglade IH, Zandbergen T, Kah O. Origin of the pituitary innervation in the goldfish. Cell Tissue Res. 1993; 273(2):345-55.

Anjos HDB, Anjos CR. Biologia reprodutiva e desenvolvimento embrionário e larval do cardinal tetra, Paracheirodon axelrodi Schultz, 1956 (Characiformes: Characidae), em laboratório. B. Inst. Pesca, São Paulo. 2006; 32(2):151-60.

Anken R, Bourrat F. Brain Atlas of the medaka fish Oryzias latipes. Paris: INRA Editions; 1998.

Baile VV, Raut IN, Bhute YV. Organization of Olfactory system, forebrain and pituitary gland of a teleost, Notopterus notopterus. Ann Neurosci. 2008; 15(2):43-50.

Blanco-Castañeda MC. Consideraciones sobre los peces ornamentales de Colombia. In: Mojica JI, Castellanos C, Usma S, Álvarez R, editors. El libro rojo de los peces dulceacuícolas de Colombia. La Serie de Libros Rojos de Especies Amenazadas de Colombia. Bogotá: Instituto de Ciencias Naturales, Universidad Nacional de Colombia, Ministerio de Medio Ambiente. 2002. p.47-54.

Bosler O. The Organum vasculosum laminae terminalis: a cytophysiological study in the duck, Anas platyrhynchos. Cell Tissue Res. 1977; 182(3):383-99.

Braford MR, Northcutt RG. Organization of the diencephalon and pretectum of the ray-finned fishes. In: Davis RE, Northcutt RG, editors. Fish Neurobiology, Vol 2 : Higher Brain Areas and Functions. Ann Arbor, MI: University of Michigan Press; 1983. p.117-163.

Brito MFG, Bazzoli N. Oogénesis of the cardinal tetra Paracheirodon axelrodi Schultz (1956): a histological and histochemical study. Braz J Morphol Sci. 2009; 26(1):14-18.

Burton S, Kaiser H, Hecht T. The potential of artemia-mediated delivery of a gonadotropin- releasing hormone analogue to induce ovulation in the cardinal tetra (Paracheirodon axelrodi). Aquarium Sci Conserv. 1998; 2(2):89-92.

Butler A, Hodos W. Comparative vertebrate neuroanatomy: evolution and adaptation. 2nd ed. New York: John Wiley, Sons Inc; 2005.

Caldas ML, Ricaurte O, Rodríguez G, Amaya J. Microscopía óptica de alta resolución "MOAR". Bogotá: Instituto Nacional de Salud; 1993.
Canadian Council on Animal Care (CCAC). CCAC guidelines on: the care and use of fish in research, teaching and testing. Ottawa: CCAC guidelines; 2003.

Castañeda DC, Tovar O, Hurtado H. Estudio morfométrico del nervio óptico de tiburoncito (Ariopsis seemanni). Int $\mathrm{J}$ Morphol. 2013; 31(1):184-88.

CCI. Informe de Pesca y Acuicultura. Sistema de Información de la Corporación Colombiana Internacional (CCI) [Internet]. Bogotá, Colombia; 2010 [cited 2012 May 16]. Available from: http://www.cci.org.co/cci/cci_x/datos/BoletinesIncoder/ Publicaciones/Informecompleto2010.pdf

Cerdá-Reverter JM, Canosa LF. Neuroendocrine systems of the fish brain. In: Bernier NJ, Kraak GVD, Farrel AP, Brauner CJ, editors. Fish neuroendocrinology. London: Academic Press; 2009. p.3-47.

Cerdá-Reverter JM, Zanuy S, Muñoz-Cueto JA. Cytoarchitectonic study ofthe brain of a perciform species, the sea bass (Dicentrarchus labrax). II. The diencephalon. J Morphol. 2001; 247(3):229-51.

COPESCAL. Pesca Ornamental en América Latina-Estado, Tendencias y Desafíos Futuros. Comisión de Pesca Continental para América Latina (COPESCAL) [Internet]. Bogotá, Colombia; 2009. [cited 2012 May 23]. Available from: http:// www.ibcperu.org/doc/isis/11159.pdf

Ekengren B. The Nucleus preopticus and the Nucleus lateralis tuberis in the roach Leuciscus rutilus. Z Zellforsch Mikrosk Anat. 1973; 140(3):369-88.

Fryer JN, Maler L. Hypophysiotropic neurons in the goldfish hypothalamus demonstrated by retrograde transport of horseradish peroxidase. Cell Tissue Res. 1981; 218(1):93-102.

Fryer JN, Peter RE. Hypothalamic control of ACTH secretion in goldfish. III. Hypothalamic cortisol implant studies. Gen Comp Endocrinol. 1977; 33(2):215-25.

Gomes CC, Costa FG, Borella MI. Distribution of GnRH in the brain of the freshwater teleost Astyanax altiparanae. Micron. 2013; 52-53:33-38.

Gómez-Ramírez E, Obando MJ, Tovar MO, Caldas ML, Hurtado H. Estudio histológico del tracto digestivo del neón cardenal Paracheirodon axelrodi (Characidae). Int J Morphol. 2011; 29(3):782-86.

Gómez-Segade P, Gómez-Segade LA, Anadón-Alvarez R. Quantification of the annual cycle of the preoptic magnocellular nucleus of the teleost Gaidropsarus mediterraneus and Coris julis. Acta Microsc. 1986; 9:67-73.

GraphPad Software [Computer software]. San Diego, California; 2007. Available from: http://www.graphpad.com

Greenwood AK, Wark AR, Fernald RD, Hofmann HA. Expression of arginine vasotocin in distinct preoptic regions is associated with dominant and subordinate behaviour in an African cichlid fish. Proc R Soc B. 2008; 275(1649):2393-402.

Gridley MF. 1960. Manual of histologic and special staining techniques. 2nd ed. New York: McGraw Hill Book Company Inc; 1960.

Ishikawa Y, Yoshimoto M, Ito H. A brain atlas of a wild-type inbred strain of the medaka, Oryzias latipes. Fish Biol J Medaka. 1999; 10:1-26. 
Kah O, Anglade I, Leprêtre E, Dubourg P, Monbrison D. The reproductive brain in fish. Fish Physiol Biochem. 1993; 11(1):85-98.

Kapoor BG, Khanna B. Ichthyology handbook. New York: Springer; 2004.

Kawauchi H, Sower SA, Moriyama S. The neuroendocrine regulation of prolactin and somatolactin secretion in fish. In: Bernier NJ, Kraak GVD, Farrel AP, Brauner CJ, editors. Fish Neuroendocrinology, Vol 28. London: Academic Press; 2009. p: 197-234.

Leatherland JF, Dodd JM. Types of secretory neurons in the preoptic nucleus of the European eel Anguilla Anguilla L. Nature. 1967; 216(5115):586-87.

Lederis K. Fine structure and hormone content of the hypothalamo-neurohypophysial system of the rainbow trout (Salmo irideus) exposed to sea water. Gen Comp Endocrinol. 1964; 4(6):638-61.

Mancera-Rodríguez NJ, Álvarez-León R. Comercio de peces ornamentales en Colombia. Acta Biol Colomb. 2008; 13(1):23-52.

Meek J, Nieuwenhuys RD. Holosteans and teleost. In: Nieuwenhuys $\mathrm{RD}$, Donkelaar HJ, Nicholson C, editors. The central nervous system of vertebrates: an introduction to structure and function. Berlin: Springer-Verlag; 1998. p.759-937.

Mukuda T, Ando M. Brain atlas of the japanese eel: comparison to other fishes. Mem Fac Integrated Arts and Sci. 2003; 29(Ser. IV):1-25.

Nakai Y, Naito N. Uptake and bidirectional transport of peroxidase injected into the blood and cerebrospinal fluid by ependymal cells of the median eminence. In: Knigge KM, Scott DE, Kobayashi H, 1shii S, editors. Brain-endocrine interaction. The ventricular system. 2nd ed. Int. Basel: Karger; 1975. p.94-108.

Nieuwenhuys R, Donkelaar JH, Nicholson C. The central nervous system of vertebrates: an introduction to structure and function. Berlin: Springer-Verlag; 1998.

Norris DO. Vertebrate endocrinology. 4th ed. Amsterdam: Academic Press; 2007.

Obando-Bulla MJ, Gómez-Ramírez E, Tovar-Bohorquez MO, Rincón L, Caldas-Martínez ML, Hurtado-Giraldo H. Estudio morfométrico y topológico del cerebro del pez neón cardenal, Paracheirodon axelrodi (Characiformes: Characidae). Actual Biol. 2013; 35(98):45-61.

Oliveira S, Souza RTY, Nunes ES, Carvalho CSM, Menezes GC, Marcon JL, Roubach R, Ono EA, Affons EG. Tolerance to temperature, $\mathrm{pH}$, ammonia and nitrite in cardinal tetra, Paracheirodon axelrodi, an Amazonian ornamental fish. Acta Amaz. 2008; 38(4):773-80.

Öztan N. The structure of the hypothalamic neurosecretory cells of Zoarces viviparus L. under the conditions of constant dark and light during the reproductive period. Z Zellforsch Mikrosk Anat. 1966; 75(1):66-82.

Palay SL. Neurosecretion. VII. The preoptico-hypophyseal pathway in fishes. J Comp Neurol. 1945; 82(2):129-43.

Palay SL. The fine structure of secretory neurons in the preoptic nucleus of the goldfish (Carassius auratus). Anat Rec. 1960; 138(4):417-43.
Perks AM. The neurohypophysis. In: Hoar WS, Randall DJ, Donaldson EM, editors. Fish Physiology, Vol 2. New York: Academic Press; 1969. p.111-205.

Peter RE, Crim LW, Billard R. A stereotaxic atlas and implantation technique for nuclei of the diencephalon of Atlantic salmon (Salmo salar) parr. Reprod Nutr Dev. 1991; 31(2):167-86.

Peter RE, Gill VE. A stereotaxic atlas and technique for forebrain nuclei of the goldfish, Carassius auratus. J Comp Neurol. 1975; 159(1):69-101.

Pogoda HM, Hammerschmidt M. Molecular genetics of the pituitary development in zebrafish. Semin Cell Dev Biol. 2007; 18(4):543-58.

Rasband WS. ImageJ, U.S [Computer software]. Bethesda, Maryland: National Institutes of Health; 2012. Available from: http://rsbweb.nih.gov/ij/download.html

Ruiz SL, Sánchez E, Tabares E, Prieto A, Arias JC, Gómez R, Castellanos D, García P, Rodríguez L, editors. Diversidad biológica y cultural del sur de la Amazonia colombianaDiagnóstico. Bogotá: Corpoamazonia, Instituto Humboldt, Instituto Sinchi, UAESPN; 2007.

Scherck CB, Moyle PB. Methods for fish biology. Bethesda,MD: American Fisheries Society; 1990.

SPSS Inc. Released 2009. PASW Statistics for Windows, Version 18.0 [Computer software]. Chicago: SPSS Inc. 2009. Available from: http:/www-01.ibm.com/software/analytics/spss/

Striedter GF. The diencephalon of the channel catfish, Ictalurus punctatus. I. Nuclear organization. Brain Behav Evol. 1990a; 36(6):329-54.

Striedter GF. The diencephalon of the channel catfish Ictalurus punctatus. II. Retinal, tectal, cerebellar and telencephalic connections. Brain Behav Evol. 1990b; 36(6):355-77.

Tovar MO, Obando MJ, Gómez E, Caldas ML, Hurtado H. 2009. Histología y morfometría del ojo del pez dulceacuícola Paracheirodon axelrodi (Characiformes: Characidae). Rev Biol Trop 2009; 57(4):1107-18.

Trudeau VL. Neuroendocrine regulation of gonadotrophin II release and gonadal growth in the goldfish, Carassius auratus. Rev Reprod. 1997; 2(1):55-68.

Tsuneki K. A survey of occurrence of about seventeen circumventricular organs in brains of various vertebrates with special reference to lower groups. J Hirnforsch. 1986; 27(4):441-70.

Walker I. The food spectrum of the cardinal tetra (Paracheirodon axelrodi, Characidae) in its natural habitat. Acta Amaz. 2004; 34(1):69-73.

Wullimann MF, Northcutt RG. Connections of the corpus cerebelli in the green sunfish and the common goldfish: a comparison of perciform and cypriniform teleosts. Brain Behav Evol. 1998; 32(5):293-316.

Wullimann MF, Rupp B, Relchert H. Neuroanatomy of zebrafish brain: a topological atlas. Basel: Birkhäuser Verlag; 1996.

Submitted October 12, 2016 Accepted February 21, 2017 by Bernardo Baldisseroto 